\section{Bonding performance of self-etch adhesives to enamel bleached with different peroxide concentrations}

\author{
Ma'an M. Nayif (1) 1, 2, Masayuki Otsuki@ 3, Junji Tagami@ 3, 4. \\ The aim of this study was to evaluate the micro-shear bond strength ( $\mu \mathrm{SBS}$ ) \\ of one and two steps self-etch adhesive systems after enamel bleaching with \\ photo-activated bleaching systems of different hydrogen peroxide (HP) \\ concentration. Occlusal enamel of forty intact human molars were flattened \\ and assigned into four groups. GI Unbleached, GII, GIII, and GIV were \\ bleached with Pyrenees (3.5\% HP), GC TiON (20\% HP), and Hi-Lite (35\% HP) \\ respectively. Enamel treatment with one and two steps self-etch adhesives \\ (Clearfil S3 Bond- S3, and Clearfil SE Bond-SE) then micro-tubes were fixed \\ on enamel and filled with AP-X composite $(n=5)$. Bond was tested with the \\ universal testing machine. Data were analyzed using two-way ANOVA and \\ Tukey's tests at $5 \%$ level of significance. The $\mu$ SBS was significantly \\ different between adhesives $(F=154.46 ; p<0.05)$ and bleaching systems \\ $(F=77.33 ; p<0.05)$ with significant interaction. Specimens bonded with S3 \\ shows a significantly lower $\mu$ SBS than those bonded with $S E(p<0.05)$ in all \\ groups. For both adhesives the bleached groups demonstrate lower $\mu \mathrm{SBS}$ \\ than unbleached except specimens bleached with Pyrenees and bonded with \\ SE ( $p>0.05)$. A significant difference was observed between groups of the \\ bleaching systems $(p<0.05)$. Different peroxide concentrations photo- \\ activated bleaching systems adversely affect $\mu \mathrm{SBS}$ of one and two steps self- \\ etch adhesives. Low concentration system (Pyrenees) does not influence the \\ bond strength of two steps adhesive.
}

1 Department of Conservative Dentistry, College of Dentistry, Mosul University, Mosul, Iraq.

${ }^{2}$ AlNoor University College, Bartella, Iraq.

${ }^{3}$ Cariology and Operative Dentistry, Department of Restorative Sciences, Graduate School of Medical and Dental Sciences, Tokyo Medical and Dental University, 1-5-45 Yushima, Bunkyo-ku, Tokyo 113-8549, Japan.

4 Global Center of Excellence program; International Research Center for Molecular Science in Tooth and Bone Diseases, Tokyo Medical and Dental University, 1-5-45 Yushima, Bunkyo-ku, Tokyo 113-8549, Japan.

Correspondence: Ma'an M. Nayif, (Assistant professor). Tel.: +964-07710447575 E-mail: mmnayif@yahoo.com

Key Words: Micro-shear bond strength, Bleaching, Self-etch adhesives

\title{
Introduction
}

Teeth's bleaching is an economical and conservative method to reverse unpleasant dental discolorations. In-office or power bleaching is one of the commonly used techniques because of their efficacy, short time consuming, and immediate result. The success of in-office bleaching relies on the high peroxide concentration of $25-35 \%$ formulation to induce high oxidative power. Currently, the photo- activated in-office bleaching systems gains high popularity due to their efficiency even with low peroxide releasing capability in a range of concentrations (3.5\% to 35\%). Its action powered by energizing the bleach material through adding an activator or colorant to improve light absorption from various sources like halogen, LED or laser $(1,2)$.

Depending on the bleaching outcome, a case may require replacement of the old restorations or use composite or porcelain veneers. Several reports indicated a reduction in the enamel restoration bond when performed shortly after bleaching. One of the strongly suggested reasons for lowered bond is the presence of residual peroxide/oxygen within enamel pores that will interfered with resin polymerization mechanism compromising resin tags quality and attachment (3). Based on this assumption, successful attempts were carried out to reverse weak bond via minimizing the retained peroxide and /or other oxygen radicals by application of a reducing agent, delay bonding, treating enamel with alcohol or acetone based adhesive (4-6). With all measures the question is raised as whether adopting an agent of low peroxide level can overcome or at least inhibit the detrimental effect on enamel bonding since the diffusion within dental tissue is largely governed by the concentration gradient. In addition, the procedure will eliminate concern about safety as the cytotoxicity was also influenced by the concentration (7).

The self-etch adhesive systems form a reliable bond with a fewer steps, and operative time and can be a good clinical alternative to older system uses a separate technique of etching then bonding (8). Based on application steps such systems may employ a two-steps of hydrophilic primer followed by solvent-free hydrophobic adhesive or more developed of one step which blends hydrophilic and hydrophobic monomers with water and organic solvent into one bottle solution (all-in-one). Although the all in one system is easy to use than two steps but it exhibited lower performance due to the water 
content needed to maintain their acidity (9). A remarkable polymerization inhibitory effect was reported in water contains adhesive a factor may control the bonding behavior variation between one step and two-steps in response to the detrimental effect of bleaching (6). A recent report demonstrates that bond strength stability of self-etch adhesive systems is more sensitive to bleaching process in comparison to other adhesives (10). Adopting photo-catalytic molecules like visible light TiO2 could speed oxidation and enhancing efficiency, enabling the reduction of peroxide. The superiority of the two-steps self-etch adhesive over one-step was reported. However, the concern about the benefit of using two-step and low peroxide photo-activated regimes to overcome the undesirable effect remains. According to our knowledge, there is limited information that compares the adhesive ability of one- and two-step selfetch adhesive systems after bleaching with low level peroxided photo activated agents (11). Therefore, the purpose of this study was to evaluate and compare the $\mu \mathrm{SBS}$ of one and two-steps self-etch adhesive systems without selective etching to enamel bleached with different in-office photo-activated bleaching systems releasing various $\mathrm{H}_{2} \mathrm{O}_{2}$ concentrations. The null hypothesis to be tested was that the differences between the one and two step adhesive systems and bleaching systems will not affect the $\mu$ SBS of the resin composite.

\section{Materials and methods}

Specimen preparation:

After approval by ethical committee (no.341/11-06-2019), forty intact human molars were cleaned with pumice and roots were resected with diamond saw (Isomet, Buehler Ltd., Lake Bluff, IL, USA) under copious water. The enamel of the occlusal surfaces was wet ground with 600-grit SiC paper to create a standardized smear layer and flat enamel surfaces. Surfaces were washed and dried with oil free triple syringe.

\section{Experimental groups and bleaching procedure:}

Specimens were randomly assigned into following groups: GI without bleaching while GII, GIII, and GIV were bleached with three in-office photo activated bleaching systems of various $\mathrm{H}_{2} \mathrm{O}_{2}$ releasing ability: (Pyrenees, Mitsubishi Gas Chemical Co. Inc., Japan.) 3.5\% $\mathrm{H}_{2} \mathrm{O}_{2}$; ( GC TiON in-office, GC America, USA) $20 \% \mathrm{H}_{2} \mathrm{O}_{2}$; and (Shofu Hi-Lite office, Kyoto, Japan) 35\% $\mathrm{H}_{2} \mathrm{O}_{2}$ Table 1. Bleaching systems were prepared and applied over enamel surfaces as manufacturer's instruction. Systems were photo-activated with a halogen light unit of $700 \mathrm{~mW} / \mathrm{cm}^{2}$ irradiance (Optilux 501, Demetron; Danbury, CT, USA). Unit irradiation was checked with radiometer (Jetlite light tester, J. Morita, Mason Irvine, CA, USA), then the treated enamel was washed and dried with triple syringe.

Table 1: Bleaching systems used in this study.

\begin{tabular}{|c|c|c|c|c|}
\hline & Agent & Main Component & $\mathrm{H}_{2} \mathrm{O}_{2} \%(\mathrm{pH})$ & Application \\
\hline Pyrenees & & & \multirow{3}{*}{$3.5 \%(6.0)$} & \multirow{3}{*}{$\begin{array}{l}\text { Solution } 1 \& 2 \text { were mixed } \\
\text { for } 1 \text { min, Applied in } 2 \mathrm{~mm} \\
\text { thick, irradiated for } 5 \mathrm{~min} \\
\text { total, washed and dried. } \\
\text { Procedure repeated three } \\
\text { times. }\end{array}$} \\
\hline & Solution 1 & $\begin{array}{c}\mathrm{H}_{2} \mathrm{O}_{2}<6 \% \text {, stabilizer } \mathrm{pH} \\
\text { adjuster }<6 \% \text {; Pure water }\end{array}$ & & \\
\hline & Solution 2 & $\begin{array}{c}\mathrm{TiO}_{2}<1 \% \text {; stabilizer }<5 \% \\
\text { pure water, other }\end{array}$ & & \\
\hline \multirow[t]{4}{*}{ GC TiON } & & & \multirow{4}{*}{$20 \%$ (neutral) } & \multirow{4}{*}{$\begin{array}{c}\text { Reactor applied and air } \\
\text { blown. Syringes A\&B were } \\
\text { mixed, Applied, irradiated } \\
\text { for } 1 \text { min, left for } 5 \text { min, } \\
\text { washed and dried. } \\
\text { Procedure repeated three } \\
\text { times. }\end{array}$} \\
\hline & Reactor & $\begin{array}{l}\text { Ethanol, } \mathrm{TiO}_{2} \text {, thickener, } \\
\mathrm{pH} \text { conditioner, water }\end{array}$ & & \\
\hline & Syringe A & $35 \% \mathrm{H}_{2} \mathrm{O}_{2}$ & & \\
\hline & Syringe B & $\begin{array}{c}\text { 30\% carbamide peroxide, } \\
\text { glycol solvente, thickener, } \\
\text { Ph conditioner }\end{array}$ & & \\
\hline \multirow[t]{3}{*}{ Hi-Lite } & & & \multirow{3}{*}{$35 \%(4)$} & \multirow{3}{*}{$\begin{array}{l}\text { Powder and liquid mixed, } \\
\text { small a applied for } 5 \mathrm{~min} \text { and } \\
\text { irradiation for } 3 \mathrm{~min} \text {. } \\
\text { Mixture was kept for } \\
\text { another } 2 \text { min then removed, } \\
\text { washed and dried. The } \\
\text { procedure was repeated for } \\
\text { three times. }\end{array}$} \\
\hline & Powder & $\begin{array}{l}\text { Potassium persulphinate, } \\
\text { manganese sulfate, } \\
\text { monohydrate, hydrated } \\
\text { amorphous silica, mixed } \\
\text { sodium and calcium salt }\end{array}$ & & \\
\hline & Liquid & $35 \% \mathrm{H}_{2} \mathrm{O}_{2}$, water & & \\
\hline
\end{tabular}




\section{Bonding procedure:}

Groups were divided into two sub-groups and bonded with one and two steps self-etch adhesives (Clearfil S3 Bond- S3 \& Clearfil SE Bond-SE, Kuraray Medical Inc., Tokyo, Japan.) ( $n=5)$. For SE bond the primer was applied over enamel for 20 seconds, spread and dried with a mild air blast followed by adhesive. For the S3 bond the adhesive was applied for 20 seconds and dried. Specimen received five translucent micro-tubes of $0.75 \mathrm{~mm}$ internal diameter and $0.5 \mathrm{~mm}$ high then adhesives were photo irradiated with halogen light unit for 10 seconds. Tubes were filled with a hybrid resin composite (Clearfil AP-X, Kuraray Medical Inc., Tokyo, Japan) and photo irradiated for 40 seconds. The composition of adhesives and restorative materials are shown in Table 2. The integrity of the bonded resin composite cylinders was examined under a light microscope and any defective bond was excluded. After 24 hours of storage at $37{ }^{\circ} \mathrm{C}$, each specimen was fixed into the testing device with a cyanoacrylate adhesive of the tabletop universal testing machine (EZ Test, Shimadzu, Kyoto, Japan). A thin stainless steel wire (0.2 $\mathrm{mm}$ in diameter) was fitted at the enamel composite interface and loaded at $1.0 \mathrm{~mm} / \mathrm{min}$ until bond failure. The $\mu \mathrm{SBS}$ was calculated by dividing the fracture load by the surface area and result expressed in MPa.

Table 2: Self-etch adhesive systems and resin composite used in the study.

\begin{tabular}{|c|c|}
\hline Material & Composition \\
\hline Clearfil S3 bond (One-step) & $\begin{array}{l}\text { MDP, HEMA, bis-GMA, dl-Camphorquinone, water, ethanol, silanated colloidal } \\
\text { silica. }\end{array}$ \\
\hline Clearfil SE bond (two-step) & $\begin{array}{c}\text { Primer: MDP, HEMA, dimethacrylate hydrophilic, Camphorquinone, N, N- } \\
\text { diethanol-p-toludine, water. } \\
\text { Adhesive: MDP, bis-GMA, HEMA, dimethacrylate hydrophobic, } \\
\text { Camphorquinone, N,N-diethanol-p-toludine, silanated colloidal silica. }\end{array}$ \\
\hline Clearfil AP-X & $\begin{array}{l}\text { Barium glass, Silica, Colloidal silica, Silicon dioxide, }(71 \text { vol. } \%, 0.1-15 \mu \mathrm{m}) \text {, Bis- } \\
\text { GMA, TEGDMA, photoinitiator }\end{array}$ \\
\hline
\end{tabular}

Statistical analysis:

The data of $\mu$ SBS were analyzed using two-way ANOVA to assess the influence of both parameters bleaching and adhesive systems and their interaction using the statistical package for social science (SPSS 20, SPSS Inc., Chicago, IL, USA). Tukey's HSD was used as post-hoc test. All tests were performed at a $5 \%$ level of significance.

\section{Fracture mode analysis:}

Interfaces of all groups were evaluated for fracture mode and ten debonded regions were randomly selected from each group and photographed under scanning electron microscope (JSM-5310, JEOL, Tokyo, Japan) at x150 and x1500 magnification. Mode of failure was classified into three types: adhesive failure (when enamel exposed); cohesive failure in resin materials (adhesive or resin composite remain); and mixed failure (combination of adhesive and cohesive). The surface area ratios of each failure type were calculated. The distributions of failure modes were subjected to a non-parametric test to compare group's difference.

\section{SEM observation:}

For observation of the changes within bleached enamel surfaces an additional two specimens were prepared from each group and treated as those used for $\mu$ SBS test groups. After the rinsing and dehydration procedures, the enamel surfaces were coated with gold and observed under SEM to evaluate alteration in surface morphology. Photographs were recorded at magnification x150 and x1500.

\section{Results}

Means and standard deviations of the $\mu$ SBS are summarized in Table 3. Two-way ANOVA demonstrated that the $\mu \mathrm{SBS}$ was significantly different according to the adhesive types $(F=77.33 ; p<$ $0.05)$ and bleaching systems $(F=154.46 ; p<0.05)$ with a significant interaction in between $(F=16.59 ; p$ $<0.05$ ). Tukey's test indicated that $\mu$ SBS of the resin composite bonded with both adhesives to the enamel bleached with all systems were significantly lower than those bonded to unbleached enamel 
(control) except specimens bonded with two-step Clearfil SE bond after bleaching with Pyrenees system $(p>0.05)$. Both unbleached and bleached specimens bonded with Clearfil S3 have demonstrated significantly lower $\mu S B S$ values in comparison to those bonded with the $S E$ bond $(p<0.05)$. A significant difference was recorded between three bleaching systems regardless of adhesive system (one or twostep) $(p<0.05)$. Failure mode percentages displayed significant variations between adhesive types and bleaching conditions $(p<0.05)$ (Figure 1$)$. Bleached groups demonstrated predominantly adhesive failures. The failure was more predominant in $\mathrm{Hi}$-Lite than other agents and in groups bonded with one step than two-steps that revealed higher cohesive (Figure 2). Pyrenees associated SE failure was lower than TiON and $\mathrm{Hi}$-Lite but similar to unbleached. While Pyrenees associated S3 show a higher adhesive percentage than unbleached but lower than Hi-Lite.

Table 3: Mean and (SD) of $\mu$ SBS for both adhesive systems in unbleached and bleached enamel groups (MPa).

\begin{tabular}{lcccc}
\hline \multicolumn{1}{c}{ Adhesive } & Unbleached & Pyrenees & GC TiON & Hi-Lite \\
\hline Clearfil SE & $38.0(5.6)^{\mathrm{A}, \mathrm{a}}$ & $37.3(4.3)^{\mathrm{A}, \mathrm{a}}$ & $28.2(5.1)^{\mathrm{B}, \mathrm{a}}$ & $22.9(4.6)^{\mathrm{C}, \mathrm{a}}$ \\
Clearfil S$^{3}$ & $33.2(3.3)^{\mathrm{A}, \mathrm{b}}$ & $18.3(4.4)^{\mathrm{B}, \mathrm{C}, \mathrm{b}}$ & $20.7(6.6)^{\mathrm{B}, \mathrm{b}}$ & $15.6(4.3)^{\mathrm{C}, \mathrm{b}}$
\end{tabular}

Means with different upper case letters within each adhesive system and lower case letters for each bleaching condition were significantly diferente
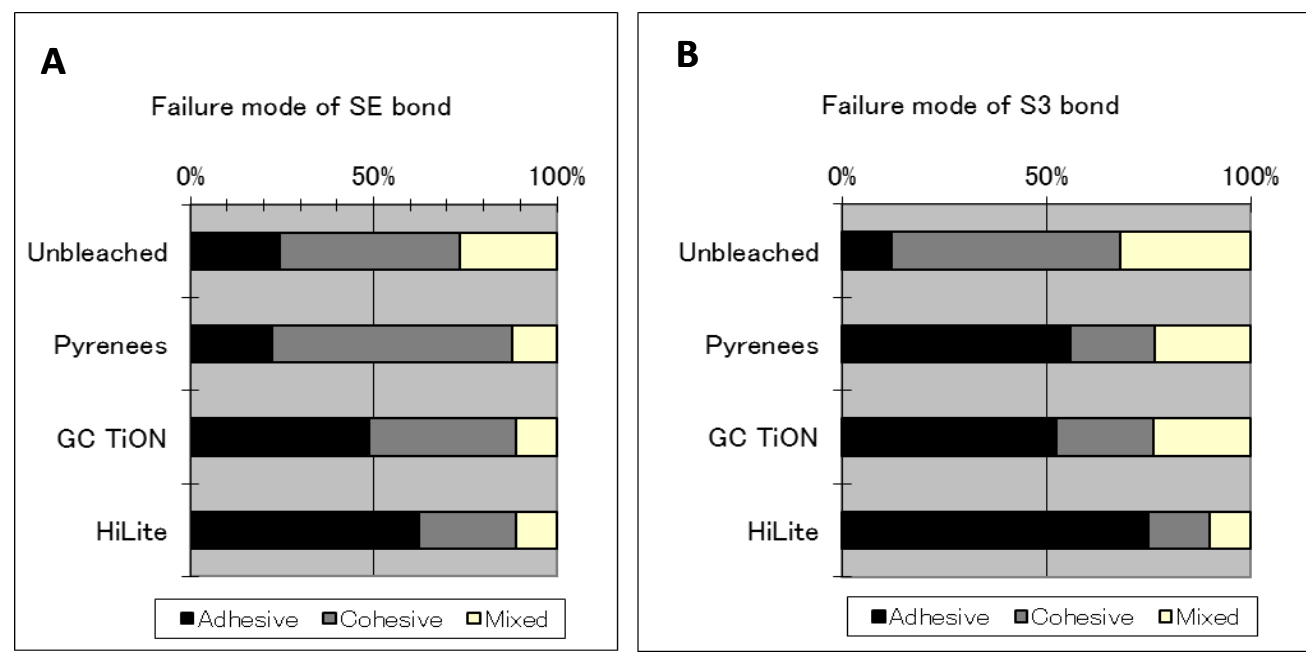

Figure 1. The percentage distribution of resin composite failure mode bonded with two $(A)$ and onestep (B) self-etch adhesives for unbleached (control) and bleached enamel groups.
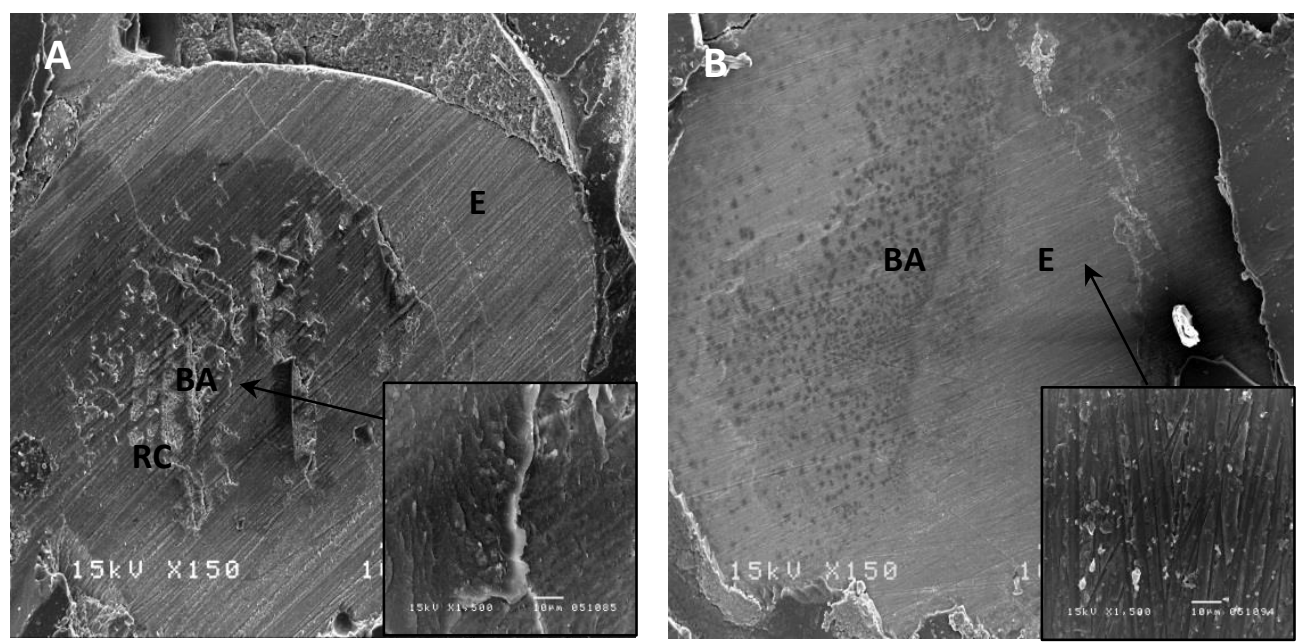

Figure 2. Representative micrograph of debonded interfaces show $(A)$ cohesive failure predominance seen at $x 150$ within interface of specimen bleached with Pyrenees and bonded with two-steps Clearfil $\mathrm{SE}$ bond. Area of exposed enamel $\mathrm{E}_{1}$ Resin composite remaining $\mathrm{RC}$, and thick layer of bond agent $\mathrm{BA}$ magnified at $\times 1500$, and (B) adhesive failure predominance at $\times 150$ from specimen bleached with $\mathrm{Hi}-$ Lite and bonded with one step Clearfil S3. Numerous dark spots spread over wide area of interface may indicate poorly polymerized bonding agent BA. The exposed enamel can be seen over whole interface. A higher magnification at $x 1500$ confirms the exposed enamel $E$. 


\section{SEM observation:}

Pyrenees showed no obvious surface changes in comparison to unbleached enamel specimens (Figure $3 \mathrm{A \& B}$ ) while enamel bleached with GC TiON and Hi-Lite systems displayed definitive changes in surface texture with amorphous chucky enamel appearance and surface porosities (Figure 3 C\&D).
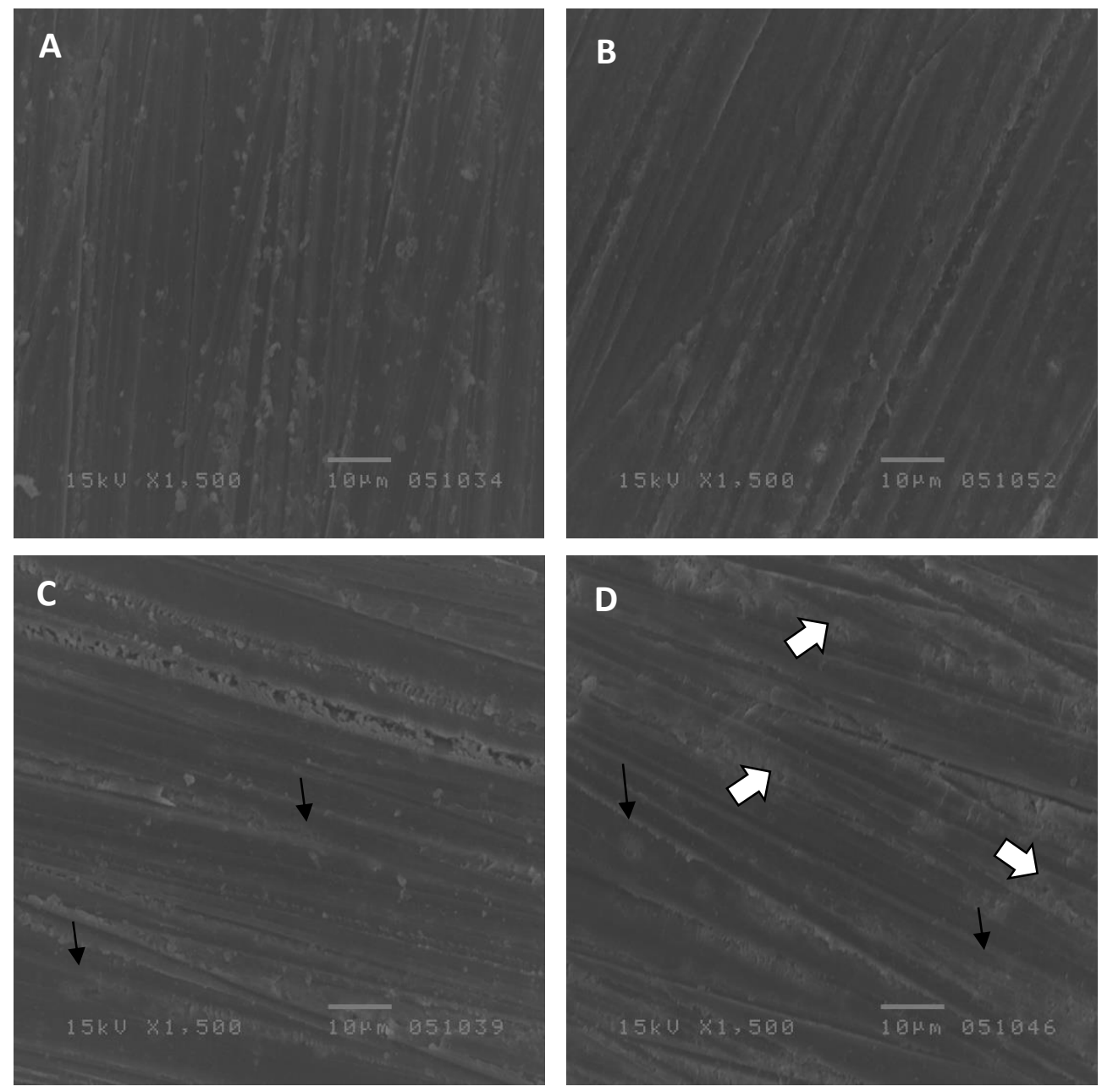

Figure 3. Representative photomicrograph of surface texture for (A) unbleached enamel reveal scratches, (B) enamel specimen bleached with Pyrenees show similar pattern to control with no obvious changes in texture, (C) GC TiON show slight changes with few number of white patches (line arrows) and (D) specimen bleached with Hi-Lite system revealed clear white patches with a chucky appearance (line arrows) and porosities (block arrows).

\section{Discussion}

The majority of teeth bleaching systems depend on $\mathrm{H}_{2} \mathrm{O}_{2}$ as a predominant and essential component. Due to simplicity and efficiency of self-etching adhesive many clinicians may encourage using for teeth restoration shortly following bleaching. This study was designed to evaluate effect of three in-office photo-activated bleaching systems elaborating various levels of $\mathrm{H}_{2} \mathrm{O}_{2}$ concentration on the enamel $\mu \mathrm{SBS}$ of two self-etch adhesive systems (One step and two-steps). Clinically in in-office bleaching the agent is applied on intact enamel surface. A procedure was not followed in this study. Flat enamel surface was prepared for the purpose of uniform bonding and standardization of bond test. Originally, the procedures of $\mu \mathrm{SBS}$ propose application of adhesive followed by air blasting for better distribution and solvent dryness. Similar steps where followed in our study without delimitation technique a possible reason for the high incidence of cohesive failures. Shimaoka et al. (12) where found that with delimitation there is a lack of cohesive failure with a higher incidence of adhesive. Similar to the other studies the bond strengths of both adhesives presented in this study were substantially reduced following enamel bleaching with all systems $(9,11,13)$ except group bleached with Pyrenees and bonded with SE bond. The precluding of selective acid etching of enamel from the adhesion strategy should be 
considered as one limitation in this study and comparable research may be necessary to verify the significance of this step. Bleached groups produced adhesive failure more frequently than unbleached unlike interface of group bonded with SE bond after bleaching with Pyrenees show similar pattern to control. The reserved $\mathrm{H}_{2} \mathrm{O}_{2}$ within enamel pores will breakdown to release oxygen and water that diffuse and probably trapped within the hybrid and adhesive layer results in incomplete polymerization or interfering with resin impregnation $(14,15)$. Incomplete polymerization was confirmed by differential calorimeter over bleached enamel (3). Optimal adhesives polymerization is an important parameter for bond durability since lower mechanical properties accompanied a low percentage of monomer to polymer conversion (16). Within overall groups the two-steps Clearfil SE adhesive produced consistently and significantly stronger $\mu$ SBS than one step Clearfil S3 bond. Screening the data has demonstrated that the highest $\mu \mathrm{SBS}$ value recorded in one step adhesive failed to approximate even the lowest value in two-steps. A recent study has confirmed the advantage of Clearfil SE bond over one step after bleaching with photo-activated system (13).Compositional variation between the two adhesives may influence the result as Clearfil S3 combine the water and ethanol solvent with monomer resin blend thus called all-in-one adhesive a simplification necessitates increasing in the hydrophilicity of the system. Water rich adhesive can be detrimental to bond efficiency and stability $(17,18)$. Presence of ethanol in one step was unable to counteract the adverse effect of residual peroxide as a proposed by some researches. Furthermore one step adhesives in nature are more permeable and more prone to nanoleakage thus high oxygen emanated from bleaching agents may easily trapped and compromising interface by polymerization rate inhibitory effect. SEM images displayed dark spot areas and porous aspect that might represent gaseous bubbling action suggesting the residual water and oxygen content affecting resin polymerization (Figure 2). A direct inverse correlation has been declared between the extent of polymerization of the adhesive films and permeability $(16,19)$. Although two steps adhesive composed of primer contains water to help monomer ionization air dryness can easily remove excess water from applied primer on enamel. The second bonding resin layer plays an important role in substantial reduction of water sorption and penetration within adhesive interfaces by creating a hydrophobic barrier. High rate of adhesive polymerization in two-steps adhesives has been approved (20). Previous nanoleakage study cleared up this suggestion when they found the hydrophobic monomer may not mixed with excessive amount of water (21).

Pyrenees is innovative low $3.5 \% \mathrm{H}_{2} \mathrm{O}_{2}$ in-office photo activated bleaching agent includes visiblelight titanium dioxide photo-catalytic molecules. Whitening efficiency of this agent has been investigated extensively under different light sources and in comparison with other in-office agents of highly concentrated $\mathrm{H}_{2} \mathrm{O}_{2}$. A promising result has associate activation with halogen light and when compared to agents of higher concentration $(2,22)$. The important finding of this study is the absence of the reduction in $\mu \mathrm{SBS}$ of the specimens bleached with Pyrenees and bonded with two-steps self-etch adhesive. Failure mode of these specimens was almost similar to control. This was not the case in onestep adhesive as the value of $\mu$ SBS was dramatically reduced in spite of using low peroxide bleaching agent. The reason probably related to the compositional variation and number of application step that strongly influence their polymerization rate later on bonding ability. Findings imply that the deleterious effect of low peroxide agent on the bond was dependent on the type of adhesive system an inference parallel to the recent report (13). A correlated result was also found with other study that evaluated microtensile strength of same adhesive systems used in this study after Pyrenees internal bleaching (23). The similarity in the result may indicate that bonding performance of the two-step adhesive will not affected by bleaching technique whenever low peroxide agent used. Hi-Lite is acidic powerful in-office bleaching system of $35 \% \mathrm{H}_{2} \mathrm{O}_{2}$ while GC TiON in-office is a neutral system liberates approximately $20 \%$ of $\mathrm{H}_{2} \mathrm{O}_{2}$ in the final mixture therefore it may be considered as an intermediate concentrated agent between Pyrenees and Hi-Lite. For better efficacy activity of GC TiON was compensated by initial application of reactor contains visible light TiO2 photocatalyst molecules to accelerate bleaching of the next mixture. According to the result of this study a sever decrease in $\mu \mathrm{SBS}$ was associated both agents (Hi-Lite and GC TiON) irrespective of adhesive when compared to control group. A significant difference was also recorded between two agents where the bond value in group bleached with TiON was higher than Hi-Lite. These results were irrespective to the bonding system. The variation in concentration of $\mathrm{H}_{2} \mathrm{O}_{2}$ may be one of the major reasons responsible on bond strength diversity (24). System of higher level may give rise to a more compromised resin enamel interface. A suggestion indirectly supported by bond reversibility when agent of high peroxide concentration needs a longer post bleaching waiting period than low agent. Unlu et al. (5) find that one day period was sufficient to restore bond for $10 \%$ carbamide to bleached group meanwhile one-week interval was required for $35 \% \mathrm{H}_{2} \mathrm{O}_{2}$. 
In consistency with bond strength outcomes related both systems comma the morphological alteration observed over enamel bleached with Hi-Lite agent was more pronounced than what was seen on surfaces bleached with GC TiON has another factor may partially affect bond strength result. Increased porosity manifested by an "over-etched" appearance on enamel bleached by Hi-Lite was evident. The clear etching pattern and white patches on the enamel of Hi-Lite group suggesting acid demineralization. The high concentration of $\mathrm{H}_{2} \mathrm{O}_{2}$ and low $\mathrm{pH}=4$ of $\mathrm{Hi}$-Lite solution could participate in this enamel alteration. In contrast the GC TiON has lower concentration and neutral pH which is above the critical value of enamel demineralization $(25,26)$. Based on the result of the study the null hypothesis was rejected as different systems of bleaching agent and adhesive affected the composite enamel $\mu \mathrm{SBS}$ value. One factor to be acknowledged is overlooking of non-light bleaching of the implemented systems a deprivation may need evaluation. It might be concluded that all photo-activated bleaching systems tested in this study adversely affects $\mu$ SBS of one and two steps self-etch adhesives. System of lowest $\mathrm{H}_{2} \mathrm{O}_{2}$ concentration (Pyrenees) doesn't exert harmful effect on the $\mu \mathrm{SBS}$ of composite when bonded with two-steps adhesive. Although this study addressed a promising result of Pyrenees bleaching effect in relation to adhesive dentistry but the eventual result must be interpreted with caution because the whitening efficiency of this agent in comparison to other of higher concentration was not sufficiently reported clinically and further investigation into this area is necessary.

Acknowledgment: This work was supported by Japanese Ministry of Education, Global Center of Excellence Program, and International Research Center for Molecular Science in Tooth and Bone Disease at Tokyo Medical and Dental University.

\section{Resumo}

0 objetivo deste estudo foi avaliar a resistência ao cisalhamento ( $\mu \mathrm{SBS})$ de sistemas auto-adesivos de um e dois passos após clareamento do esmalte com sistemas de clareamento foto-ativados de diferentes concentrações de peróxido de hidrogênio (HP). 0 esmalte oclusal de quarenta molares humanos intactos foi aplainado e atribuído em quatro grupos. GI Unbleached, GII, GIII, e GIV foram branqueados com Pyrenees (3,5\% HP), GC TiON (20\% HP), e Hi-Lite (35\% HP) respectivamente. Tratamento de esmalte com adesivos de um e dois passos auto-adesivos (Clearfil S3 Bond- S3, e Clearfil SE Bond-SE), depois os microtubos foram fixados no esmalte e preenchidos com composto AP-X $(n=5)$. A resistência ao cisalhamento foi testada com a máquina universal de testes. Os dados foram analisados usando os testes de ANOVA e Tukey de duas vias a um nivel de $5 \%$ de significância. $0 \mu \mathrm{SBS}$ foi significativamente diferente entre adesivos $(F=154,46 ; p<0,05)$ e sistemas de clareadores $(F=77,33 ; p<0,05)$ com interação significativa. Os espécimes colados com $S 3$ mostram um $\mu$ SBS significativamente inferior aos colados com SE $(p<0,05)$ em todos os grupos. Para ambos os adesivos, os grupos clareados demonstram $\mu \mathrm{SBS}$ inferiores aos não clareados exceto os espécimes clareados com Pyrenees e colados com SE $(p>0,05)$. Foi observada uma diferença significativa entre os grupos dos sistemas de clareamento $(p<0,05)$. Diferentes concentrações de peróxidos foto-ativados nos sistemas de clareamento afetam negativamente $\mu$ SBS dos adesivos de uma e duas etapas de auto-colagem. 0 sistema de baixa concentração (Pyrenees) não influenciou a resistência ao cisalhamento do adesivo de duas etapas. 


\section{References}

1. Bortolatto JF, Pretel H, Floros MC, Luizzi ACC, Dantas AAR, Fernandez E, et al. Low Concentration $\mathrm{H}_{2}{ }_{2} \mathrm{O}\left(_{2}\right) / \mathrm{TiON}$ in Office Bleaching: A Randomized Clinical Trial. J Dent Res 2014; 93 (7 Suppl):66S-71S.

2. Cuppini M, Leitune VCB, Souza M, Alves AK, Samuel SMW, Collares FM. In vitro evaluation of visible light-activated titanium dioxide photocatalysis for in-office dental bleaching. Dent Mater J 2019; 38:68-74.

3. Cadenaro M, Breschi L, Antoniolli F, Mazzoni A, Di Lenarda R. Influence of whitening on the degree of conversion of dental adhesives on dentin. Eur J Oral Sci 2006; 114: 257-262.

4. Cavalli V, Giannini M, Carvalho RM. Effect of carbamide peroxide bleaching agents on tensile strength of human enamel. Dent Mater 2004; 20: 733-739.

5. Unlu N, Cobankara FK, Ozer F. Effect of elapsed time following bleaching on the shear bond strength of composite resin to enamel. J Biomed Mater Res B Appl Biomater 2008; 84: 363-368.

6. Nunes TG, Ceballos L, Osorio R, Toledano M. Spatially resolved photopolymerization kinetics and oxygen inhibition in dental adhesives. Biomaterials 2005; 26: 1809-1817.

7. Redha 0, Strange A, Maeva A, Sambrook R, Mordan N, McDonald A, Bozec L. Impact of Carbamide Peroxide Whitening Agent on Dentinal Collagen. J Dent Res 2019; 98:443-449.

8. Carrilho E, Cardoso M, Marques Ferreira M, Marto CM, Paula A, Coelho AS. 10-MDP Based Dental Adhesives: Adhesive Interface Characterization and Adhesive Stability-A Systematic Review. Materials (Basel) 2019; 12:790.

9. Halabi S, Matsui N, Nikaido T, Abdo A, Burrow MF, Tagami J. Effect of two bleaching regimens on enamel bonding performance. Dent Mater J 2020 Jul 4.

10. El Mourad AM. Stability of Bonded Resin Composite Restorations to Enamel after Bleaching with 20\% Carbamide Peroxide. J Contemp Dent Pract 2019; 20:247-257.

11. Oz FD, Kutuk ZB. Effect of various bleaching treatments on shear bond strength of different universal adhesives and application modes. Restor Dent Endod. 2018; 43:e20.

12. Shimaoka AM, de Andrade AP, Cardoso MV, de Carvalho RC. The importance of adhesive area delimitation in a microshear bond strength experimental design. J Adhes Dent 2011;13:307-314.

13. Halabi S, Matsui N, Nikaido T, Burrow MF, Tagami J. Effect of Office Bleaching on Enamel Bonding Performance. J Adhes Dent 2019; 21:167-177.

14. Lai SCN, Tay FR, Cheung GSP, Mak YF, Carvalho RM, Wei SHY, et al. Reversal of compromised bonding in bleached enamel. J Dent Res 2002; 81: 477-481.

15. Sakai K, Kato J, Nakazawa T, Kameyama A, Hirai Y. The amounts of hydroxyl radicals generated by titanium dioxide and 3.5\% H2O2 under 405-nm diode laser irradiation Laser Physics 2007; 17: 10621066.

16. Cadenaro $M$, Antoniolli F, Sauro $S$, Tay FR, De Irnarda $R$, Prati $C$, et al., Degree of conversion and permeability of dental adhesives. Eur J Oral Sci 2005; 113: 525-530.

17.Tay FR, Pashley DH, Suh BI, Carvalho RM, Itthagarun A. Single-step adhesives are permeable membranes. J Dent 2002; 30: 371-382.

18. Chersoni S, Suppa P, Grandini S, Goracci $C$, Monticelli F, Yiu C, et al. In vivo and in vitro permeability of one-step self-etch adhesives. J Dent Res 2004; 83: 459-464.

19. Breschi $L$, Cadenaro $M$, Antoniolli $F$, Visintini $E_{1}$ Toledano $M$, Di Lenarda R. Extent of polymerization of dental bonding systems on bleached enamel. Am J Dent 2007; 20: 275-280.

20. Reis AF, Giannini M, Pereira PN. Influence of water-storage time on the sorption and solubility behavior of current adhesives and primer/adhesive mixtures.Oper Dent 2007; 32:53-59.

21. Nayif MM, Shimada Y, Ichinose $S$, Tagami J. Nanoleakage of current self-etch adhesives bonded to artificial carious dentin. Am J Dent 2010; 23: 279-284.

22. Kishi A, Otsuki M, Sadr A, Ikeda M, Tagami J. Effect of light units on tooth bleaching with visiblelight activating titanium dioxide photocatalyst. Dent Mater J 2011; 30:723-9.

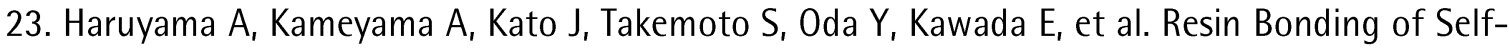
Etch Adhesives to Bovine Dentin Bleached from Pulp Chamber. Biomed Res Int. 2016;2016:1313586.

24. Akin M, Aksakalli $S$, Basciftci FA, Demir A. The effect of tooth bleaching on the shear bond strength of orthodontic brackets using self-etching primer systems. Eur J Dent 2013; 7:55-60. 
25. Lopes GC, Bonissoni L, Baratieri LN, Vieira LC, Monteiro S Jr. Effect of bleaching agents on the hardness and morphology of enamel. J Esthet \& Restor Dent 2002; 14: 24-30.

26. Pimenta-Dutra AC, Albuquerque RC, Morgan LS, Pereira GM, Nunes E, Horta MC, Silveira FF. Effect of bleaching agents on enamel surface of bovine teeth: A SEM study. J Clin Exp Dent 2017; 9:e46e50.

Received: $17 / 10 / 2020$

Accepted: $26 / 04 / 2021$ 